\title{
Both $\beta-1$ adrenoceptors and AT1 receptors may not be involved in the catecholamine-induced lethal arrhythmias
}

\begin{tabular}{|c|c|}
\hline Journal: & Canadian Journal of Physiology and Pharmacology \\
\hline Manuscript ID & cjpp-2018-0531.R1 \\
\hline Manuscript Type: & Article \\
\hline $\begin{array}{r}\text { Date Submitted by the } \\
\text { Author: }\end{array}$ & $06-N o v-2018$ \\
\hline Complete List of Authors: & $\begin{array}{l}\text { Adameova, Adriana; Faculty of pharmacy, Comenius university in } \\
\text { Bratislava, Slovakia, Department of Pharmacology and Toxicology } \\
\text { Elimban, Vijayan; Institute of Cardiovascular Sciences, } \\
\text { Ganguly, Paul; Alfaisal University, Anatomy } \\
\text { Dhalla, Naranjan; Institute of Cardiovascular Sciences, }\end{array}$ \\
\hline $\begin{array}{r}\text { Is the invited manuscript for } \\
\text { consideration in a Special } \\
\text { Issue: }\end{array}$ & 2018 IACS Cuba \\
\hline Keyword: & $\begin{array}{l}\text { Catecholamine-induced arrhythmias, } \beta<\text { sub }></ \text { sub }>\square \square \text { - } \\
\text { adrenoceptors, AT1 receptors, plasma catecholamines, receptor blockade }\end{array}$ \\
\hline
\end{tabular}

\section{SCHOLARONE" Manuscripts}




\section{Both $\beta-1$ adrenoceptors and AT1 receptors may not be involved in the catecholamine-induced lethal arrhythmias}

Adriana Adameova $^{1}$, Vijayan Elimban ${ }^{2}$, Paul K Ganguly ${ }^{2}$, Naranjan S Dhalla ${ }^{2 *}$

${ }^{1}$ Department of Pharmacology and Toxicology, Faculty of Pharmacy, Comenius University 83232 Bratislava, Odbojarov 10, Slovakia and ${ }^{2}$ Institute of Cardiovascular Sciences, St.

Boniface Hospital Albrechtsen Research Centre and Department of Physiology \& Pathophysiology, Max Rady College of Medicine, University of Manitoba, Winnipeg, Canada

Running title: Catecholamine-induced arrhythmias

\section{* Address for correspondence:}

Dr. Naranjan S. Dhalla

St. Boniface Albrechtsen Hospital Research Centre

351 Tache Avenue

Winnipeg, Manitoba, Canada R2H 2A6

Tel: (204) 235-3421

Fax: (204) 237-0347

E-mail: nsdhalla@sbrc.ca 


\begin{abstract}
Although an excessive amount of catecholamines is known to produce arrhythmias, the exact mechanisms of this derangement are not fully understood. For this purpose, Sprague-Dawley rats were treated with or without atenolol, a $\beta_{1}$-adrenoceptor blocker $(20 \mathrm{mg} / \mathrm{kg} / \mathrm{day})$, for 15 days followed by injections of epinephrine for cumulative doses of 4 to $128 \mu \mathrm{g} / \mathrm{kg}$. Another group of animals was pretreated with losartan, an angiotensin receptor (AT1) blocker (20 $\mathrm{mg} / \mathrm{kg} /$ day) for comparison. Varying degrees of ventricular arrhythmias were seen upon increasing the dose of epinephrine but the incidence or the duration of rhythm abnormalities as well as number of episodes and severity of arrhythmias were not affected upon treating the animals with atenolol or losartan. The levels of both epinephrine and norepinephrine were increased in the atenolol-treated rats but unchanged in the losartan-treated animals after the last injection of epinephrine; the severity of arrhythmias did not correlate with the circulating catecholamine levels. These results indicate that both $\beta_{1}$-adrenoceptors and AT1 receptors may not be involved in the pathogenesis of catecholamine-induced arrhythmias and support the view that other mechanisms such as oxidation products of catecholamines may play a crucial role in the occurrence of lethal arrhythmias.
\end{abstract}

\title{
Keywords
}

Catecholamine-induced arrhythmias; $\beta_{1}$-adrenoceptors; AT1 receptors; plasma catecholamines; atenolol; losartan 


\section{Introduction}

Elevated levels of circulating catecholamines have been reported in different stressful conditions such as heart failure and ischemic heart disease, which are often associated with arrhythmias (Dhalla et al. 2008; Adameova et al. 2009). In fact, an increased amount of catecholamines has been shown to provoke both atrial and ventricular arrhythmias including non-serious single premature ventricular beats as well as fatal ventricular tachycardia (Westfall and Westfall, 2006; Barta et al. 2008). Although stimulation of $\beta$-adrenoceptors and subsequent activation of cAMP/protein kinase A system has been suggested to play an important role in the pathogenesis of catecholamine-induced arrhythmias (Podzuweit, 1981); several studies employing various $\beta$-adrenoceptor blocking agents did not reveal conclusive results. In this regard, different $\beta$-blockers have been reported to be both effective and ineffective in reducing the catecholamine-induced arrhythmias (Lucchesi et al. 1966; Rosati et al. 1966; Daugherty et al. 1986; Ablad et al. 2007; Clements-Jewery et al. 2009). Since some $\beta$-blockers have been shown to exert membrane stabilizing action and intrinsic sympathetic activity, it has been indicated that these properties may contribute to the conflicting observations with these drugs on the heart (Westfall and Westfall, 2006). Moreover, unlike selective $\beta$-blockers (metoprolol and atenolol), non-selective $\beta$-blockers of the first and third generation(propranolol and carvedilol) have been shown to decrease cardiac norepinephrine spillover, an index of catecholamine release from the heart (Newton and Parker, 1996; Azevedo et al. 2001), and this action has been considered to explain the beneficial effects of $\beta$-receptor blockade. There is evidence to support that oxidation products of catecholamines also participate in the induction of arrhythmias and sudden cardiac death (Dhalla, 2018; Dhalla et al. 2010). Thus, it appears that neither the mechanisms of catecholamine-induced arrhythmias nor the direct involvement of selective $\beta$-adrenoceptor blockade are understood. 
It is pointed out that catecholamines by acting on $\beta_{1}$-adrenoceptors in juxtaglomerular cells are known to cause the release of renin, which in turn promotes the formation of angiotensin II ( Dhalla et al. 2008). Numerous studies have documented the participation of the renin-angiotensin system in the development of reperfusion - induced or myocardial infarction-induced fatal arrhythmias (Dhalla et al. 1993; Harada et al. 1998; de Langen et al 1989). Blockade of angiotensin II type 1 (AT1) receptors with losartan has also been shown to reduce the reperfusion-induced arrhythmias (de Boer et al, 2002; Lee et al. 1997; Matsuo et al. 1997). These observations suggest that the catcholmine-induced arrhythmias may also be elicited indirectly through the release of endogenous angiotensin II and participation of AT1 receptors in the myocardium. Since catecholamines released upon stimulation of the sympathetic nervous system act mainly on $\beta_{1}$-adrenoceptors whereas angiotensin formed upon stimulation of renin-angiotensin system acts on AT1 receptors in the myocardium, it is likely that the blockade of both $\beta$-adrenoceptors and AT1 receptors may prevent the catecholamine-induced arrhythmias under stressful conditions. The present study was, therefore, undertaken to test whether the blockade of $\beta_{1}$-adrenoceptors and AT1 receptors by treatment of animals with atenolol and losartan, respectively, can prevent the development of catecholamine-induced arrhythmias. In addition, the circulating catecholamine levels were measured to examine whether atenolol and losartan are capable of influencing the sympathetic activity.

\section{Materials and Methods}

\section{Animals}

This study followed the Guidelines established by the Canadian Institutes of Health Research and approved by the Animal Care Committee of the University of Manitoba. Male 
Sprague-Dawley rats weighing 250-300 g were kept at 12-h day/night cycle and fed rat chow and water ad libitum.

\section{Drug treatments and induction of arrhythmias}

Atenolol and losartan (both $20 \mathrm{mg} / \mathrm{kg}$ ) were given daily for 15 days via gastric tube $(1.8 \mathrm{~mm} \times 100 \mathrm{~mm}, 15 \mathrm{G})$ to different groups of animals. The last dose of these drugs was given 10 min before the induction of arrhythmias. The control rats received saline solution daily for 15 days. It should be mentioned that the use of $20 \mathrm{mg} / \mathrm{kg}$ doses of both atenolol and losartan in this study to ensure the blockade of $\beta_{1}$-adrenoceptors and AT1 receptors, respectively, was based on our previous work concerning the effects of these agents for attenuation of cardiac remodeling due to myocardial infarction in rats (Machackova et al. 2010; Babick et al. 2012). Furthermore, the protocol for the treatment of rats with atenolol and losartan for 15 days was carried out for adaptation of homodynamic alterations due to these drugs; this protocol is similar to that used for several agents for 2 to 4 weeks treatmwnt to study their effects on the experimentally induced arrhythmias (Barta et al. 2009; Brasil et al. 2002; Ren et al. 1998; Sethi et al. 2000; Sethi et al. 2009). It may also be noted that arrhythmias were induced by injecting cumulative doses of epinephrine in the control, atenolol- and losartan-treated rats according to the experimental design described previously (Barta et al. 2008; Sethi et al. 2009). Briefly, the tail vein of the anesthethized rats (5\% isoflurane) was cannulated and the animals were put on six-lead ECG (leads I-III, augmented vector right aVR, augmented vector left aVL, augmented vector foot aVF) monitoring system (AcqKnowladge 3.0.3 software). The rats were then injected cumulative doses of epinephrine intravenously in bolus of $4,8,16,32,64,128 \mu \mathrm{g} / \mathrm{kg}$ at $10 \mathrm{~min}$ intervals. In a separate set of experiments, cumulative doses of epinephrine were 4,8,16 and $32 \mu \mathrm{g} / \mathrm{kg}$. A 10 -min baseline and continuous ECG were recorded until the last epinephrine injection. From the ECG 
recordings, PQ, QRS, RR, and QT intervals were measured; QT was corrected for the heart rate (HR) using Bazett's formula. Epinephrine-induced arrhythmias such as, premature ventricular beats (PVBs), bigemines, salvos and ventricular tachycardias, were analyzed according to Lambeth Conventions (Walker et al. 1988; Curtis et al. 2013). Ventricular tachycardia (VT) was defined as a run of four or more consecutive ectopic beats. The incidence, (the percentage of arrhythmic occurrence per group), number of episodes (the number of particular arrhythmic events), time of onset as well as duration of PVBs and all types of ventricular arrhythmias were analyzed. In addition, each animal was evaluated by means of a 6-point arrhythmia score and an assigned number corresponded to the most severe type of arrhythmias observed in that animal. These scores were used for group analysis of the severity of arrhythmias as described previously (Adameova et al. 2007).

\section{Measurement of epinephrine, norepinephrine and dopamine}

In the anesthetized animals, blood was collected from the abdominal aorta 10 min after the last injection of epinephrine (cumulative doses of epinephrine were 4,8,16 and $32 \mu \mathrm{g} / \mathrm{kg}$ ). Plasma was immediately prepared upon centrifugation and stored at $-80^{\circ} \mathrm{C}$ until biochemical analysis was performed. The catecholamine levels were analyzed using a Bio-Rad plasma Ca reagent kit (Cat. No. 1956078) for high performance liquid chromatography method (Waters 2960 Separtaion Module) with electrochemical detection (Amperometric LC-4C detector, Bioanalytical systems) as described by Sethi et al. (2009).

\section{Statistical analysis}

Data are reported as mean \pm SEM for 6 animals per group. One-way analysis of variance (ANOVA) followed by Tukey`s multiple test was used for comparison of differences in parametric variables among the groups. The incidence of arrhythmias was expressed as 
percentage and compared by using the $2 \times 2$ chi-square test. A $p$ value $<0.05$ indicated a significant difference.

\section{Results}

The influence of the blockade of $\beta_{1}$-adrenoceptors with atenolol and AT1 receptors with losartan on ECG variables under baseline conditions are shown in Table 1. Neither atenolol nor losartan influenced the PQ and RR intervals. Both drugs tended to reduce QT and corrected QTc interval; however, this change did not reach significance. The representative baseline ECG (Figure 1A) as well as records upon injections of epinephrine are shown in (Figures 1B and 1C). No ventricular arrhythmias were seen in the control and treated experimental groups during a stabilization phase. On the other hand, intravenous injections of epinephrine provoked various types of ventricular arrhythmias including PVBs, bigemines, salvos and ventricular tachycardias. In addition, AV blockade (Mobitz type II, 2nd degree) was also seen in the epinephrine injected group.

The profile of arrhythmias including changes in PQ, RR and QT intervals as well as PVBs, bigemines, salvos and ventricular tachycardias upon epinephrine injections in the control rats was similar to that observed in our previous studies (Sethi et al, 2009); the most seen arrhythmias were PVBs. Neither the blockade of $\beta_{1}$-adrenoceptors with atenolol nor AT1 receptors with losartan attenuated the occurrence of these non-serious arrhythmias. Upon the first injection of epinephrine $(4 \mu \mathrm{g} / \mathrm{kg})$, atenolol even increased the occurrence of PVBs (Table 2). Further doses of epinephrine insignificantly increased the incidence of these arrhythmias. At the dose of $32 \mu \mathrm{g} / \mathrm{kg}$ of epinephrine injected, all atenolol-treated animals experienced PVBs, whereas higher dose of epinephrine $(64 \mu \mathrm{g} / \mathrm{kg})$ was needed to induce these arrhythmias in control animals. The increased incidence of PVBs was associated with higher mean numbers of episodes of these arrhythmias. The blockade of AT1 receptors did not 
modify the generation of PVBs; their incidence was also similar to that seen in the controls (Table 2).

The results in Figure 2 show that the incidence and number of episodes of all types of ventricular arrhythmias were dependent on the dose of injected epinephrine in control animals. This was also observed in the losartan-treated rats; both incidence and the mean number of episodes were comparable with data of the untreated group (Figures 2A, 2B). On the other hand, the incidence of arrhythmias in the atenolol-treated group was increased at 4 to $32 \mu \mathrm{g} / \mathrm{kg}$ doses of epinephrine (Figure 2A) whereas the episodes of arrhythmias were increased in these animals at $32 \mu \mathrm{g} / \mathrm{kg}$ and $64 \mu \mathrm{g} / \mathrm{kg}$ doses (Figure 2B). Although these results in the atenolol-treated group indicate that atenolol may have sensitized the heart against ventricular arrhythmias, it is evident that atenolol did not depress the catecholamine-induced arrhythmias. Furthermore, the data in Table 3 shows that neither blockade of $\beta_{1}$-adrenoceptors nor AT1 receptors were effective with respect to the modification of both the onset and duration of all ventricular arrhythmias. A detailed analysis of arrhythmias expressed as arrhythmia score revealed that the severity of arrhythmias upon epinephrine injections did not differ between the treated and non-treated groups (Figure 3A).

The effects of $\beta_{1}$-adrenoceptors and AT1 receptors blockade on circulating catecholamine (epinephrine, norepinephrine and dopamine) levels are shown in Figures 3B, 3C, 3D. The data indicated that the levels of circulating epinephrine, norepinephrine and dopamine measured upon the last injected dose of epinephrine in losartan-treated group were comparable to the levels in the control rats. On the other hand, atenolol-treatment increased the levels of both epinephrine and norepinephrine, unlike that for dopamine. However, no apparent correlation was seen among the severity of arrhythmia score (Figure 3A) and the levels of circulating epinephrine, norepinephrine and dopamine in control, atenolol-treated and losartan-treated groups (Figures 3B, 3C and 3D). 


\section{Discussion}

Previous studies from our laboratory were undertaken to study the role of both the sympathetic nerve system and the renin-angiotensin system in the development of myocardial infarction and heart failure (Sethi et al. 2004; Wang et al. 2005; Shao et al. 2005; Machackova et al. 2009). Since these diseases are characterized by the increased levels of circulating catecholamines and are often associated with arrhythmias, the present study aimed at testing the role of both $\beta_{1}$-adrenoceptors and AT1 receptors in the occurrence of epinephrine-induced arrhythmias. Such a study is also of particular significance under different stressful conditions in which plasma catecholamine levels are increased due to a release of epinephrine from the adrenal medulla and norepinephrine from nerve endings (Dhalla et al. 2008; Adameova et al. 2009). Because several investigators have reported that the increase in cardiac adrenergic drive in heart failure is due to local release of epinephrine rather than circulating norepinephrine (Goldsmith et al. 1985: Bristow et al. 1992), this study using epinephrine for the induction of arrhythmias is of particular relevance. Although epinephrine acts on both $\alpha$ and $\beta_{1}$-adrenoceptors, it has been suggested that a stimulation of $\alpha$-adrenoceptors in coronary smooth cells can be seen to induce spasm resulting in myocardial ischemia and the development of associated oxidative stress, which are known to induce heart rhythm disturbances (Dhalla et al. 2008; Adameova et al. 2009). It may be noted that ischemia/reperfusion-induced arrhythmias have been reported to occur as a consequence of oxidative stress as well as release of endogenous norepinephrine and angiotensin II from the heart (Du et al. 1999; Dhalla et al. 2000; Dhalla et al. 2008; Harada et al. 1998; Matsuo et al. 1997; Lee et al. 1997). Since the activation of $\beta_{2}$-adrenoceptors as well as $\alpha_{1}$ - adrenoceptors and AT1 receptors is also known to promote the entry of $\mathrm{Ca}^{2+}$ in cardiomyocytes, their participation in catecholamine-induced arrhythmias cannot be ruled out. Thus, it appears that the mechanisms of arrhythmogenesis due to catecholamines may be of a complex nature. 
We have observed that a selective blockade of $\beta_{1}$-adrenoceptors did not prevent the ventricular arrhythmias due to epinephrine, indicating that these receptors and subsequent cellular pathways may not be involved in the catecholamine-induced arrhythmogenesis. In fact, atenolol-treatment was observed to increase rather than to decrease the occurrence and number of episodes of ventricular arrhythmias after certain doses of epinephrine. This may be due to the tendency of atenolol to increase QT and QTc intervals, which are considered to be prognostic factors of arrhythmias (Zhu et al. 2000; Pourdjabbar et al. 2005). Although we did not measure the plasma catecholamine levels at every dose of epinephrine injection, we have observed that these levels were higher in the atenolol-treated group at $32 \mathrm{mg} / \mathrm{kg}$ dose of epinephrine in comparison to the control animals. Thus the increased incidence and episodes of arrhythmias due to catecholamines in the atenolol-treated animals may be the consequence of the action of atenolol at the sympathetic nerve terminals. Nonetheless, different studies have failed to observe the beneficial effects of $\beta$-blockers in the prevention of catecholamineassociated arrhythmias (Rosati et al. 1966; Daugherty et al. 1986, Clements-Jewery et al. 2009). It is also noteworthy that a non-selective $\beta$-blocker, propanolol, has been shown to reverse ventricular arrhythmias but the mechanism of this action was not believed to be associated with its ability to produce cardiac $\beta$-adrenergic receptor blockade (Lucchesi et al. 1966; Daugherty et al. 1986). Likewise, Ablad et al. (2007) have provided evidence that a lipophilic $\beta$-blocker, metoprolol, reduced the incidence of ventricular fibrillation (which is superior to hydrophilic atenolol) via the inhibition of $\beta_{1}$-adrenoceptors at the level of central nervous system that modulates the vagal nervous outflow. Our previous studies have highlighted a role of the oxidation products of catecholamines such as adrenochrome and oxyradicals in the induction of lethal arrhythmias (Barta et al. 2008; Singal et al. 1982; Sethi et al. 2009; Dhalla 2018). Thus, it is highly unlikely that $\beta_{1}$-adrenoceptors are involved in the pathogenesis of catecholamine-induced arrhythmias. 
A number of studies have been undertaken to evaluate a role of AT1 receptors in the development of arrhythmias. Many of these experiments have examined ischemia/reperfusion-induced arrhythmias (Liu et al. 1996; Lee et al. 1997; Zhu et al. 2000; Pourdjabbar et al. 2005), which occur as a complex consequence of other components such as endothelial dysfunction, inflammation and oxidative stress (Dhalla et al. 2000). The data presented here show that a blockade of AT1 receptors with losartan prior to an induction of catecholamine-induced arrhythmias does not attenuate its occurrence or severity. This is in agreement with a study of Pourdjabbar et al. (2005), who showed that pre- and perimyocardial infarction treatment with losartan exerts no beneficial effect on the development of ventricular arrhythmias. On the other hand, some investigators have reported that pretreatment with blockers of AT1 receptors was capable of decreasing the number of episodes of ischemia/reperfusion-induced ventricular tachycardia and ventricular fibrillation (Lee et al. 1997; Zhu et al. 2000). Such a reduction in the occurrence of ventricular arrhythmias due to ischemia/reperfusion has been documented in rats pretreated with the low doses of losartan (2 and $5 \mathrm{mg} / \mathrm{kg}$ ) (Liu et al. 1996; Lee et al. 1997). In the present study, we have used $20 \mathrm{mg} / \mathrm{kg}$ of losartan dose for investigating its effects on epinephrine-induced arrhythmias and its ineffectiveness shows that the mechanisms of catecholamine-induced arrhythmias may be different from those for the ischemia/reperfusion-induced arrhythmias.

In our study, we have also shown that the levels of circulating catecholamines including norepinephrine and epinephrine in the atenolol-treated group, unlike losartantreated group, were significantly increased. In contrast, other $\beta$-blockers, such as propranolol and carvedilol, have been shown to decrease cardiac spillover in subjects with congestive heart failure (Newton and Parker, 1996; Azevedo et al. 2001). On the other hand, in our another study, atenolol at both low and high doses was found to decrease the plasma epinephrine levels, whereas only a high dose of this $\beta$-blocker was able to reduce 
norepinephrine in rats with heart failure due to myocardial infarction (Machackova et al. 2009). Such differences between the effects of atenolol in the present study and other reports may be due to differences in the modification of reactivity of sympathetic nerve terminals in congestive heart failure and arrhythmias due to excessive amounts of catecholamines. Likewise, the ability of particular $\beta$-blockers to inhibit selectively or nonselectively various types of $\beta$-receptors may also underlie the differences in the cardiac catecholamines spillover. It appears that atenolol pretreatment in animals sensitize the presynaptic $\beta_{1-\text { adrenoreceptors }}$ on preterminal nerve endings and adrenal medulla to release noradrenaline and epinephrine, respectively, and this may account for the augmentation of the circulating catecholamines. Nonetheless it should be noted that the severity of arrhythmogenesis did not differ among the groups while catecholamine levels were increased in the atenolol-treated rats; this can be seen to indicate that the circulating catecholamines may not correlate with cardiac injury associated with arrhythmias. In fact, other mechanisms, like the development of oxidative stress and the formation of adrenochrome as the products of catecholamines oxidation may participate in the observed arrhythmogenesis (Singal et al. 1982; Adameova et al. 2009; Sethi et al. 2009; Dhalla et al. 2008).

$\beta$-blockers are now well established to play a pivotal role in the successful management of heart diseases associated with high circulating catecholamine levels. By acting on myocardial remodeling and decreasing in the sympathetic activity, $\beta$-blockers have been shown to decrease mortality significantly (Newton and Parker, 1996; Azevedo et al. 2001, Machackova et al. 2009). Likewise, blockers of ATI receptors are very effective in amelioration of cardiac dysfunction in heart failure (Sethi et al 2004; Shao et al. 2005; Dhalla et al. 2009). However, in this study we have shown that both atenolol and losartan did not exert any effect on the catecholamine-induced serious ventricular tachyarrhythmias. It seems that the blockade of $\beta_{1}$-adrenoceptors or AT1 receptors may attenuate structural remodeling 
and hemodynamic dysfunction in heart failure (Sethi et al 2004; Shao et al. 2005; Machackova et al. 2009) rather than protecting the heart against electrophysiological disturbances.

In conclusion, the results of this study indicate that both $\beta_{1}$-adrenoceptors and AT1 receptors are unlikely to be involved in the mechanisms associated with catecholaminemediated arrhythmias. Furthermore, the levels of circulating catecholamines do not seem to correlate with the severity of arrhythmias. It is suggested that other indirect effects of catecholamines, such as oxidative stress generated by oxidation of catecholamines as well as inflammation may underlie their pro-arrhythmic activity. We have also suggested that high levels of circulating catecholamines promote the formation of aminochrome, which via the occurrence of intracellular $\mathrm{Ca}^{2+}$-overload has been shown to exhibit arrhythmogenic properties (Singal et al. 1982; Dhalla, 2018). Thus, it is not surprising that both $\beta 1$ adrenoceptor blocker and AT1 blocker failed to prevent lethal arrythmias in the face of high circulating catecholamines.

Limitations of this study: In view of the negative results regarding the effects of both atenolol and losartan, it can be argued that some protocol should be included in the study to define the mechanism of catecholamine-induced arrhythmias. However, it is noteworthy that excessive amount of epinephrine has been shown to produce adrenochrome (Dhalla et al. 1989; Sethi et al. 2009), which was reported to induce arrhythmias under the similar experimental conditions (Singal et al. 1982; Dhalla et al. 2008; Adameova et al. 2009). Thus the present study should be considered as an extension of our previous work. On the other hand, since epinephrine is known to activate not only $\beta_{1}$-adrenoceptors but also $\beta_{2}$-and $\alpha_{1}$ adrenoceptors; it is possible that these $\beta_{2}$-and $\alpha_{1}$-adrenoceptor mechanisms may be involved in the genesis of arrhythmias observed in this study. Furthermore, an ACE inhibitor could also 
be used to verify if the oxidation products of catecholamines are involved in the induction of arrhythmias. Because we did not examine the effects of both $\beta_{2}$ - and $\alpha_{1}$-receptor blockade or any ACE inhibitors, the lack of information in this regard can indeed be seen as a limitation of this study. Therefore, experiments with these interventions should be carried out in future to fully understand the mechanisms of catecholamine-induced arrhythmias.

\section{Acknowledgement}

The financial support for this work as well as the infrastructure for this project were provided by the St. Boniface General Hospital Research Foundation.

\section{Conflict of interest}

The authors declare that there is no conflict of interest associated with this work. 


\section{References}

Ablad, B., Bjurö, T., Björkman, J.A.,and Edström, T. 2007. Prevention of ventricular fibrillation requires central beta-adrenoceptor blockade in rabbits. Scand. Cardiovasc. J. 41: 221-229.

Adameova, A., Abdellatif, Y., and Dhalla, N.S. 2009. Role of the excessive amounts of circulating catecholamines and glucocorticoids in stress-induced heart disease. Can. J. Physiol. Pharmacol. 87: 493-514.

Adameova, A., Kuzelova, M., Andelova, E., Faberova, V., Pancza, D., Svec, P., et al. 2007. Hypercholesterolemia abrogates an increased resistance of diabetic rat hearts to ischemiareperfusion injury. Mol. Cell. Biochem. 295: 129-136.

Azevedo, E.R., Kubo, T., Mak, S., Al-Hesayen, A., Schofield, A., Allan, R., et al. 2001. Nonselective versus selective beta-adrenergic receptor blockade in congestive heart failure: differential effects on sympathetic activity. Circulation. 104: 2194-2199.

Babick, A., Chapman, D., Zieroth, S., Elimban, V., and Dhalla N.S. 2012. Reversal of subcellular remodelling by losartan in heart failure due to myocardial infarction. J Cell Mol Med. 16: 2958-2967

Barta, J., Sanganalmath, S.K., Kumamoto, H. Takeda, N., Édes, I., and Dhalla, N.S. 2008. Antiplatelet agents sarpogrelate and cilostazol affect experimentally-induced ventricular arrhythmias and mortality. Cardiovasc. Toxicol. 8: 127-135. 
Brasil, D., Temsah, R.M., Kumar, K., Kumamoto, H., Takeda, N., and Dhalla, N.S. 2002. Blockade of 5-HT2A receptors by sarpogrelate protects the heart against myocardial infarction in rat. J Cardiovasc Pharmacol Therapeut. 7: 53-59.

Bristow, M.R., Minobe, W., Rasmussen, R, Larrabee, P., Skerl, L., Klein, J.W., et al. 1992. Beta-adrenergic neuroeffector abnormalities in the failing human heart are produced by local rather than systemic mechanisms. J. Clin. Invest. 89: 803-815.

Clements-Jewery, H., Andrag, E., Hearse, D.J., and Curtis, M.J. 2009. Complex adrenergic and inflammatory mechanisms contribute to phase 2 ventricular arrhythmias in anaesthetized rats. Br. J. Pharmacol. 156: 444-453.

Curtis, M.J., Hancox, J.C., Farkas, A., Wainwright, C.L., Stables, C.L., Saint, D.A., Clements-Jewery, H., Lambiase, P.D., Billman, G.E., Janse, M.J., Pugsley, M.K., Ng, G.A., Roden, D.M., Camm, A.J., and Walker, M.J. 2013. The Lambeth Conventions (II): guidelines for the study of animal and human ventricular and supraventricular arrhythmias. Pharmacol Ther. 139: 213-248.

Daugherty, A., Frayn, K. N., Redfern, W. S., and Woodward, B. 1986. The role of catecholamines in the production of ischaemia-induced ventricular arrhythmias in the rat in vivo and in vitro. Br. J. Pharmacol. 87: 265-277.

de Boer, R. A., van Geel, P.P., Pinto, Y. M., Suurmeijer, A.J. H.,. Crijns, H. J. G., van Gilst, W.H., et al, 2002. Efficacy of angiotensin II type 1 receptor blockade on reperfusion-induced 
arrhythmias and mortality early after myocardial infarction is increased in transgenic rats with cardiac angiotensin II type 1 overexpression, J. Cardiovasc.Pharmacol.39:610-619

de Langen, C.D.J., de Graeff, P.A., van Gilst, W.H., Bell, K.J., Kingma, J.H., and Wesseling, H. 1989. Effects of angiotensin II and captopril on inducible sustained ventricular tachycardia two weeks after myocardial infarction in the pig. J Cardiovasc Pharmacol. 13:186-191.

Dhalla, K.S., Ganguly, P.K., Rupp, H., Beamish, R.E. and Dhalla, N.S. 1989. Measurement of adrenolutin as an oxidation product of catecholamines in plasma. Mol Cell Biochem. 87:85-92.

Dhalla, N.S., Afzal, N., Beamish, R.E., Naimark, B., Takeda, N., and Nagano, M. 1993. Pathophysiology of cardiac dysfunction in congestive heart failure. Can. J. Cardiol. 9: 873887.

Dhalla, N.S., Dent, M.R., and Arneja A.S. 2008. Pathogenesis of catecholamine-induced cardiomyopathy, In: Cardiovascular Toxicology, 4th edition, (Acosta, D., Jr, ed.), Informa Healthcare USA Inc., New York, pp. 207-262.

Dhalla, N.S., Elmoselhi, A.B., Hata, T., and Makino, N. 2000. Status of myocardial antioxidants in ischemia-reperfusion injury. Cardiovasc. Res. 47: 446-456.

Dhalla, N.S., Saini-Chohan, H.K., Rodriguez-Leyva, D., Elimban, V., Dent, M.R., and Tappia, P.S. 2009. Subcellular remodelling may induce cardiac dysfunction in congestive heart failure. Cardiovasc. Res. 81: 429-438. 
Dhalla, N.S. 2018. Formation of aminochrome leads to cardiac dysfunction and sudden cardiac death. Circ. Res. 123: 409-411.

Dhalla, N.S., Adameova, A., and Kaur, M. 2010. Role of catecholamine oxidation in sudden cardiac death. Fundam. Clin. Pharmacol. 24: 539-546.

Du, X.J., Cox, H.S., Dart, A.M., and Esler, M.D. 1999. Sympathetic activation triggers ventricular arrhythmias in rat heart with chronic infarction and failure. Cardiovasc. Res. 43: 919-929.

Harada, K., Komuro, I., Hayashi, D., Sugaya, T., Murakami, K., and Yazaki, Y., 1998. Angiotensin II type 1a receptor is involved in the occurrence of reperfusion arrhythmias. Circulation. 97:315-317.

Goldsmith, S.R., Francis, G.S., and Cohn, J.N. 1985. Norepinephrine infusions in congestive heart failure. Am. J. Cardiol. 56: 802-804.

Lee, Y.M., Peng, Y.Y., Ding, Y.A., and Yen, M.H. 1997. Losartan attenuates myocardial ischemia-induced ventricular arrythmias and reperfusion injury in spontaneously hypertensive rats. Am. J. Hypertens. 10: 852-858.

Liu, Y.H., Yang, X.P., Sharov, V.G., Sigmon, D.H., Sabbath, H.N., and Carretero, O.A. 1996. Paracrine systems in the cardioprotective effect of angiotensin-converting enzyme inhibitors on myocardial ischemia/reperfusion injury in rats. Hypertension. 27: 7-13. 
Lucchesi, B.R., Whitsitt, L.S., and Brown N. L. 1966. Propranolol (inderal) in experimentally-induced cardiac arrhythmias. Can. J. Physiol. Pharmacol. 44: 543-547.

Matsuo, K., Kumagai, K., Annoura, M., Yamanouchi, Y., Handa, K., Nakashima, Y., Hiroki, T., and Arakawa, K. 1997. Effects of an angiotensin II antagonist on reperfusion arrhythmias in dogs. PACE, 20 (Pt 1):938-945.

Machackova, J., Sanganalmath, S.K., Barta, J., Dhalla, K.S., and Dhalla, N.S. 2010. Amelioration of cardiac remodeling in congestive heart failure by beta-adrenoceptor blockade is associated with depression in sympathetic activity. Cardiovasc. Toxicol. 10:9-16.

Newton, G.E., and Parker, J.D. 1996. Acute effects of beta 1-selective and nonselective betaadrenergic receptor blockade on cardiac sympathetic activity in congestive heart failure. Circulation. 94: 353-358.

Podzuweit, T. 1981. Catecholamine-cyclic AMP- $\mathrm{Ca}^{2+}$-induced ventricular tachycardia in the intact pig heart. Basic Res. Cardiol. 75: 772-779.

Pourdjabbar, A., Parker, T.G., Nguyen, Q.T., Desjardins, J.F., Lapointe, N., Tsoporis, J.N., et al. 2005. Effects of pre-, peri-, and post-myocardial infarction treatment with losartan in rats: effect of dose on survival, ventricular arrhythmias, function, and remodeling. Am. J. Physiol. Heart and Circ. Physiol. 288: H1997-H2005.

Ren, B., Lukas, A., Shao, Q., Guo, M., Takeda, N., Aitken, R.M., and Dhalla, N.S. 1998. 
Electrocardiographic changes and mortality due to myocardial infarction in rats with or without imidapril treatment. J Cardiovasc Pharmacol Therapeut. 3:11-22.

Rosati, R.A., Alexander, J.A., Wallace, A.G., Sealy, W.C., and Young, W.G. Jr. 1966. Failure of beta-adrenergic blockade to alter ventricular fibrillation threshold in the dog. Evidence for extra-adrenergic effects of pronethalol. Circ. Res. 19: 721-725.

Sethi, R., Adameova, A., Dhalla, K.S., Khan, M., Elimban, V., and Dhalla, N.S. 2009. Modification of epinephrine-induced arrhythmias by N-acetyl-L-cysteine and vitamin E. J. Cardiovasc. Pharmacol. Therap. 14: 134-142.

Sethi, R., Shao, Q., Ren, B., Saini, H.K., Takeda, N., and Dhalla, N.S. 2004. Changes in betaadrenoceptors in heart failure due to myocardial infarction are attenuated by blockade of renin-angiotensin system. Mol. Cell. Biochem. 263: 11-20.

Sethi, R., Takeda, N., Nagano, M., and Dhalla, N.S. 2000. Beneficial effects of vitamin E treatment in acute myocardial infarction. J Cardiovasc Pharmacol Therapeut. 5:51-58,

Shao, Q., Ren, B., Elimban, V., Tappia, P.S., Takeda, N., \& Dhalla, N.S. 2005. Modification of sarcolemmal $\mathrm{Na}^{+}-\mathrm{K}^{+}$-ATPase and $\mathrm{Na}^{+} / \mathrm{Ca}^{2+}$ exchanger expression in heart failure by blockade of renin-angiotensin system. Am. J. Physiol. Heart and Circ. Physiol. 288: H26372646. 
Singal, P.K., Dhillon, K.S., Beamish, R.E., Kapur, N., and Dhalla, N.S. 1982. Myocardial cell damage and cardiovascular changes due to i.v. infusion of adrenochrome in rats. Br. J. Exp. Pathol. 63: 167-176.

Walker, M.J., Curtis, M.J., Hearse, D.J., Campbell, R.W., Janse, M.J., Yellon, D.M., et al. 1988. The Lambeth Conventions: guidelines for the study of arrhythmias in ischaemia infarction and reperfusion. Cardiovasc. Res. 22: 447-455.

Wang, X., Sentex, E., Saini, H.K., Chapman, D., and Dhalla, N.S. 2005. Upregulation of betaadrenergic receptors in heart failure due to volume overload. Am. J. Physiol. Heart and Circ. Physiol. 289: H151-159.

Westfall, T.C. and Wesfall, D.P. 2006. Adrenergic agonists and antagonists, In:Goodman \& Gilman`s The Pharmacological Basis of Therapeutics. 11th edition, (Brunton, L. L., Lazo, J.S., \& Parker, K.L. eds), McGraw-Hill Companies, Inc., USA, pp. 243-284.

Zhu, B., Sun, Y., Sievers, R.E., Browne, A.E., Pulukurthy, S., Sudhir, K., et al. 2000. Comparative effects of pretreatment with captopril and losartan on cardiovascular protection in a rat model of ischemia-reperfusion. J.Am. Coll. Cardiol. 35: 787-795. 


\section{Legend to Figures}

\section{Figure 1}

Representative ECG records showing the most frequent arrhythmias developed upon an administration of cumulative $(4,8,16$, and $32 \mu \mathrm{g} / \mathrm{kg}$ ) doses of epinephrine. (A) baseline rat ECG, (B) premature ventricular beat (PVBs), salvos and ventricular tachycardia (VT), (C) atrio-ventricular blockade (Mobitz type II, 2nd degree).

\section{Figure 2}

A and B: Influence of atenolol and losartan pretreatments on the incidence (A) and the mean number of episodes (B) of all types of ventricular arrhythmias induced by cumulative doses $(4,8,16,32,64$ and $128 \mu \mathrm{g} / \mathrm{kg}$ )of epinephrine. Atenolol and losartan (both $20 \mathrm{mg} / \mathrm{kg} / \mathrm{day}$ ) or saline was given orally by gavage for 15 days before intravenous epinephrine injections. The parametric values are mean $\pm \mathrm{SEM}, \mathrm{n}=6$ in each group. ${ }^{*} \mathrm{P}<0.05$.

\section{Figure 3}

A: Influence of atenolol and losartan pretreatment on the severity of ventricular arrhythmias (arrhythmia score) induced by cumulative doses (48, 16, and $32 \mu \mathrm{g} / \mathrm{kg}$ ) of epinephrine. Atenolol and losartan $(20 \mathrm{mg} / \mathrm{kg} /$ day $)$ or saline was given orally by gavage for 15 days before intravenous epinephrine injections. B, C and D: The plasma catecholamine (epinephrine, norepinephrine and dopamine) levels after the last injected dose of epinephrine in control, atenolol- and losartan-treated rats. Atenolol and losartan $(20 \mathrm{mg} / \mathrm{kg} / \mathrm{day})$ or saline was given orally by gavage for 15 days before intravenous epinephrine injections. The values are mean \pm SEM, $\mathrm{n}=6$ in each group. $* \mathrm{P}<0.05$. 
Table 1. Duration of different parameters of cardiac intervals upon blockade of $\beta_{1^{-}}$ adrenoreceptors and AT1 receptors before epinephrine injections.

\begin{tabular}{lccc}
\hline & \multicolumn{3}{c}{ Duration of heart intervals (s) } \\
\cline { 2 - 4 } & Control & Atenolol & Losartan \\
\hline PQ & $0.037 \pm 0.001$ & $0.038 \pm 0.001$ & $0.036 \pm 0.001$ \\
QRS & $0.062 \pm 0.002$ & $0.060 \pm 0.002$ & $0.058 \pm 0.001$ \\
QT & $0.098 \pm 0.003$ & $0.094 \pm 0.001$ & $0.091 \pm 0.004$ \\
RR & $0.183 \pm 0.006$ & $0.186 \pm 0.007$ & $0.186 \pm 0.004$ \\
QTc & $0.230 \pm 0.007$ & $0.219 \pm 0.006$ & $0.214 \pm 0.008$ \\
\hline
\end{tabular}

Atenolol and losartan (both $20 \mathrm{mg} / \mathrm{kg} /$ day) or saline were given orally by gavage for 15 days. The values are mean \pm SEM. $n=6$ in each group. 
Table 2. Infuence of atenolol and losartan pretreatments on the incidence and mean number of episodes of PVBs induced by cumulative doses of epinephrine.

\begin{tabular}{|c|c|c|c|c|c|c|}
\hline \multirow{3}{*}{$\begin{array}{l}\text { Dose of } \\
\text { Epi } \\
(\mu \mathrm{g})\end{array}$} & \multicolumn{3}{|c|}{ Incidence PVBs } & \multicolumn{3}{|c|}{ Mean number of episodes PVBs } \\
\hline & & & & & & \\
\hline & Control & Atenolol & Losartan & Control & Atenolol & Losartan \\
\hline 4 & $1 / 6(17 \%)$ & $5 / 6(83 \%)^{*}$ & $2 / 6(33 \%)$ & $1.33 \pm 1.15$ & $2.00 \pm 0.68$ & $0.50 \pm 0.34$ \\
\hline 8 & $3 / 6(50 \%)$ & $4 / 6(67 \%)$ & $3 / 6(50 \%)$ & $1.00 \pm 0.61$ & $1.33 \pm 0.52$ & $1.50 \pm 0.72$ \\
\hline 16 & $3 / 6(50 \%)$ & $4 / 6(67 \%)$ & $4 / 6(67 \%)$ & $3.33 \pm 2.58$ & $2.50 \pm 0.85$ & $1.83 \pm 0.65$ \\
\hline 32 & $5 / 6(83 \%)$ & $6 / 6(100 \%)$ & $5 / 6(83 \%)$ & $4.00 \pm 3.71$ & $12.83 \pm 2.00$ * & $6.83 \pm 2.65$ \\
\hline 64 & $6 / 6(100 \%)$ & $6 / 6(100 \%)$ & $5 / 6(83 \%)$ & $8.00 \pm 3.95$ & $12.83 \pm 2.99$ & $7.17 \pm 2.10$ \\
\hline 128 & $6 / 6(100 \%)$ & $6 / 6(100 \%)$ & $6 / 6(100 \%)$ & $14.17 \pm 5.58$ & $13.33 \pm 3.42$ & $17.33 \pm 2.74$ \\
\hline
\end{tabular}

Atenolol and losartan (both $20 \mathrm{mg} / \mathrm{kg} /$ day) or saline were given orally by gavage for 15 days before intravenous epinephrine injections. The values are mean \pm SEM. $n=6$ in each group. ${ }^{*} \mathrm{P}<0.05$ Ate vs. $\mathrm{C}$. 
Table 3. Infuence of atenolol and losartan pretreatments on the duration and onset of all types of arrhythmias induced by cumulative doses of epinephrine.

\begin{tabular}{lcccccc}
\hline Dose of Epi & \multicolumn{3}{c}{ Duration of arrhythmias(s) } & \multicolumn{3}{c}{ Onset of arrhythmias(s) } \\
\cline { 2 - 6 }$(\mu \mathrm{g})$ & Control & Atenolol & Losartan & Control & Atenolol & Losartan \\
\hline 4 & $0.17 \pm 0.14$ & $0.33 \pm 0.10$ & $0.08 \pm 0.06$ & $20.17 \pm 14.73$ & $23.83 \pm 7.33$ & $11.83 \pm 7.51$ \\
8 & $0.15 \pm 0.08$ & $0.20 \pm 0.09$ & $0.26 \pm 0.13$ & $24.67 \pm 18.85$ & $11.00 \pm 3.56$ & $10.67 \pm 5.28$ \\
16 & $1.40 \pm 1.26$ & $2.26 \pm 1.60$ & $0.40 \pm 0.15$ & $17.67 \pm 8.45$ & $14.50 \pm 3.06$ & $13.67 \pm 5.99$ \\
32 & $1.16 \pm 0.46$ & $3.38 \pm 1.22$ & $2.06 \pm 0.92$ & $21.50 \pm 7.55$ & $24.67 \pm 8.80$ & $16.33 \pm 2.79$ \\
64 & $2.45 \pm 0.59$ & $7.00 \pm 3.77 *$ & $2.17 \pm 0.70$ & $21.17 \pm 3.11$ & $14.33 \pm 2.43$ & $19.33 \pm 6.51$ \\
128 & $16.38 \pm 6.18$ & $8.94 \pm 6.19$ & $8.08 \pm 2.11$ & $17.17 \pm 1.62$ & $10.83 \pm 0.70$ & $10.17 \pm 0.87$
\end{tabular}

Atenolol and losartan (both $20 \mathrm{mg} / \mathrm{kg} /$ day) or saline were given orally by gavage for 15 days before intravenous epinephrine injections. The values are mean \pm SEM. $n=6$ in each group. ${ }^{*} \mathrm{P}<0.05$ Atenolol vs. $\mathrm{C}$. 


\section{A. BaselineECG}

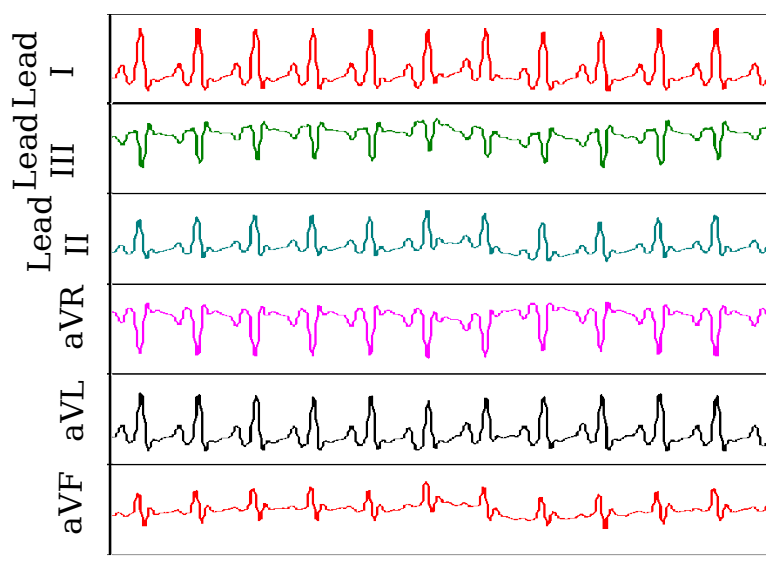

\section{B. Epinephrine (32}

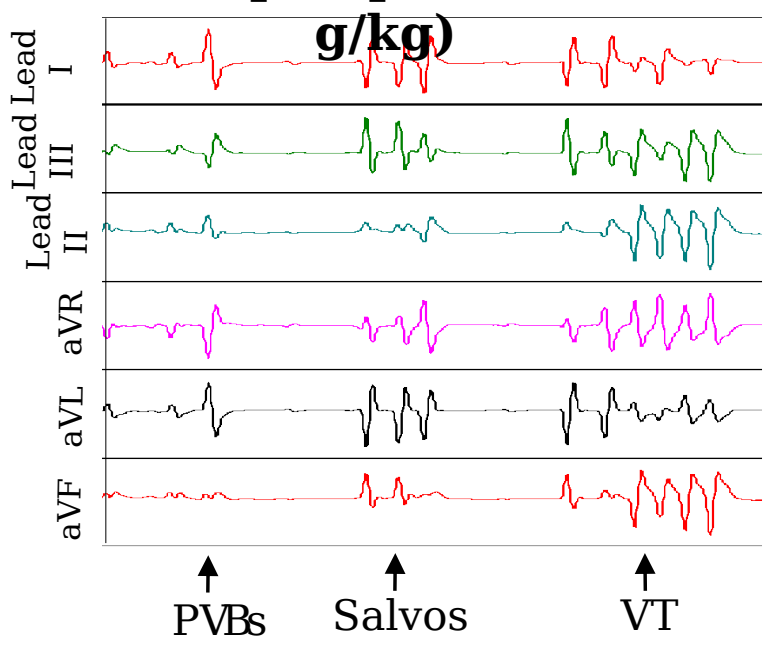

\section{Epinephrine (32}

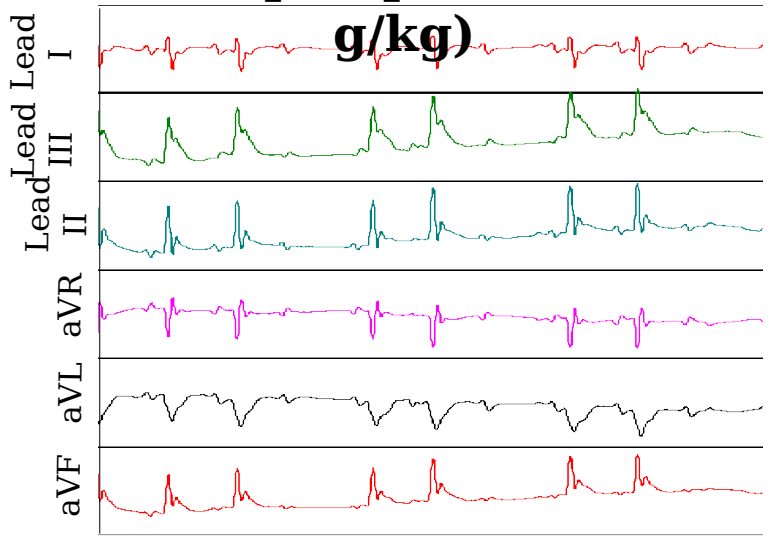

AV blockade 
$\square$ Con $\quad$ Ate Los

A. Incidenceof Ventricular Arrhythmias
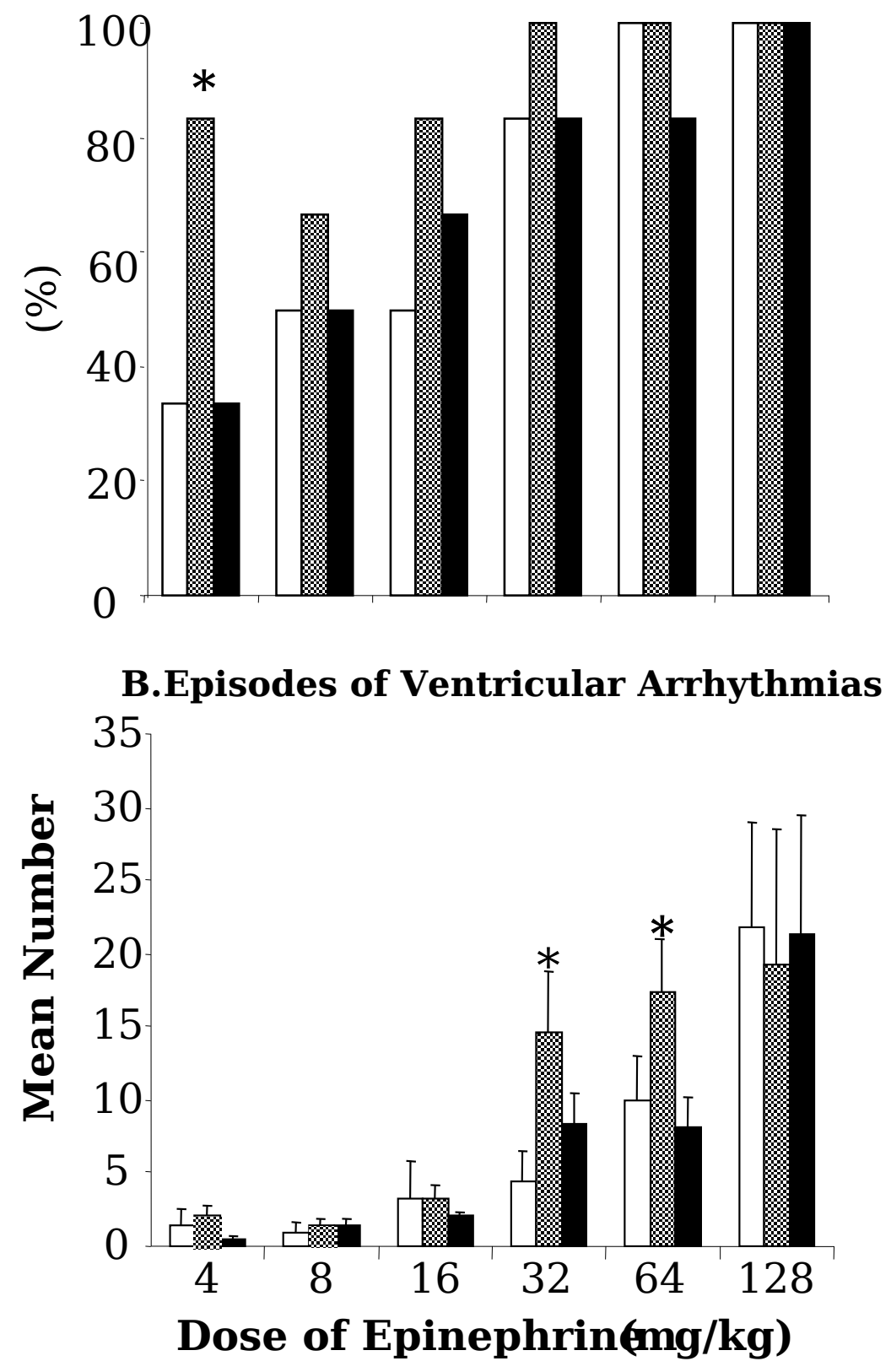

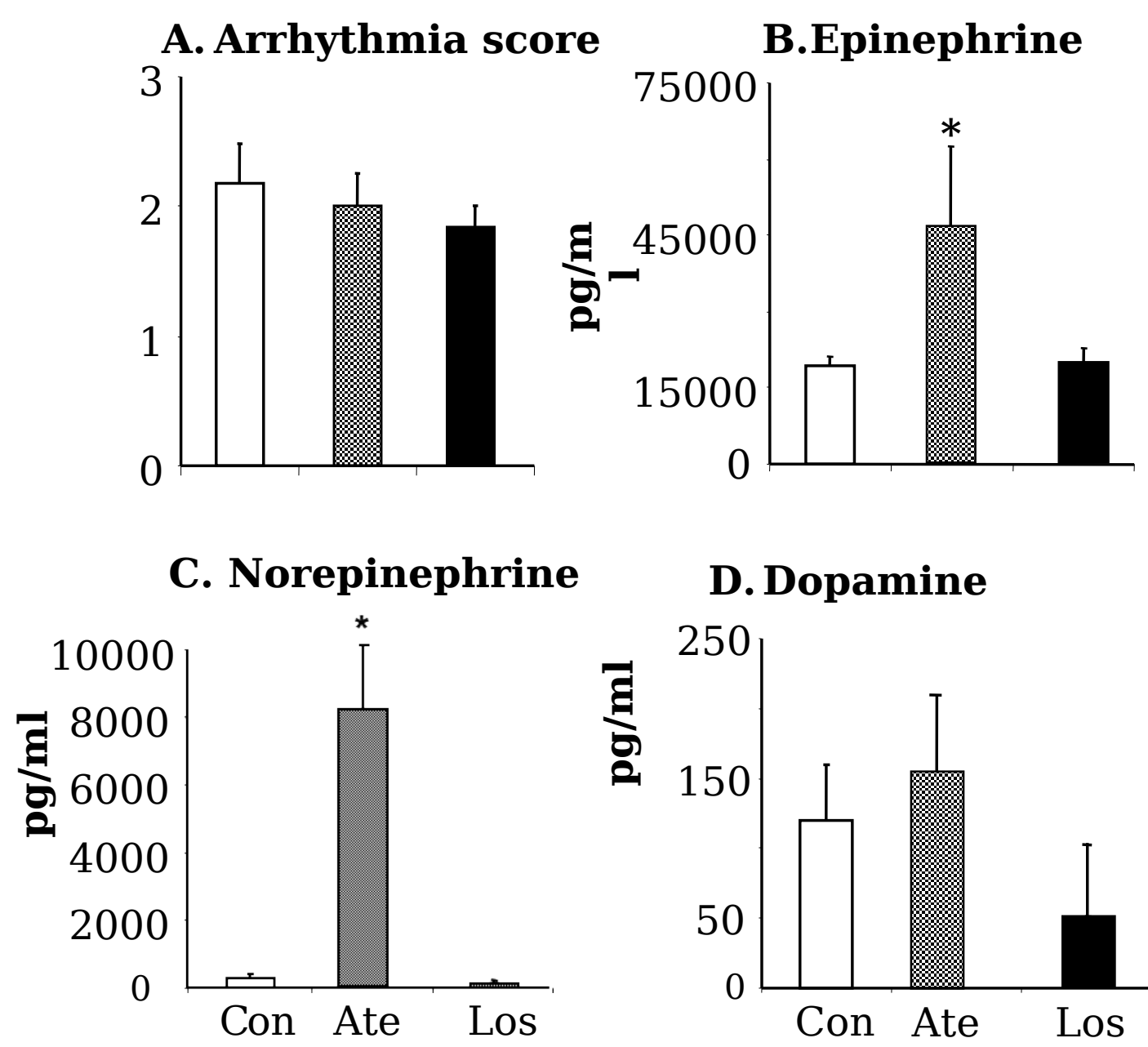

D. Dopamine

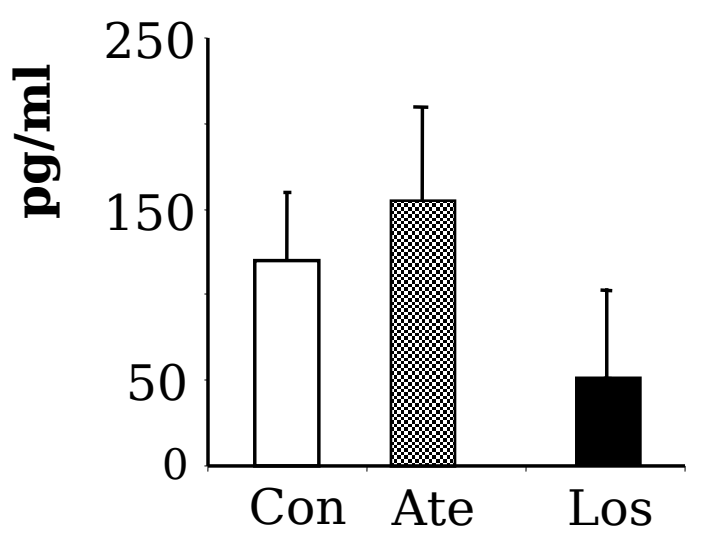

